\title{
Effects of English and Persian Subtitles on Oral Fluency and Accuracy of Intermediate Iranian EFL Learners
}

\author{
Fatemeh Khosh Ayand \\ English Department, Shahreza Branch, Islamic Azad University, Shahreza, Iran \\ E-mail: Fatemeh.KhoshAyand@gmail.com \\ Sajad Shafiee (Corresponding author) \\ English Department, Shahrekord Branch, Islamic Azad University, Shahrekord, Iran \\ E-mail: s.shafiee@iaushk.ac.ir
}

Received: 05-12-2015

Published: 01-05-2016
Accepted: 09-02-2016

doi:10.7575/aiac.ijalel.v.5n.3p.133
Advance Access Published: March 2016

URL: http://dx.doi.org/10.7575/aiac.ijalel.v.5n.3p.133

\begin{abstract}
The present study attempted to explore the effects of employing English and Persian subtitles on the Iranian EFL learners' oral fluency and accuracy. From among 100 intermediate Iranian EFL learners in Donyaye Sokhan Language Institute in Isfahan, Iran, 60 were selected in the wake of administering the PET (Preliminary English Test) as the participants of the study, and were randomly divided into two experimental groups and one control group. The control group was exposed to movies without any subtitles, while one of the experimental groups watched movies with English subtitles and the other watched movies with Persian subtitles. The format of pretest and posttest was semi-structured interview in which students answered several questions. Fluency scores were derived out of the formula suggested by Yuan and Ellis (2003), while accuracy was quantified through Foster and Skehan's (1996) procedure. The analysis of the obtained data via SPSS indicated that (a) the successful performance of the participants in the experimental groups was shown to be attributable to using subtitles as a method for improving oral fluency and accuracy, (b) there were no significant differences between the two experimental groups, and (c) oral fluency and accuracy of the control group did not ameliorate significantly in the course of this experiment.
\end{abstract}

Keywords: English Subtitles, Persian Subtitles, Oral Fluency, Oral Accuracy, EFL Learners

\section{Introduction}

Languages consist of four main skills: speaking, reading, writing, and listening. Speaking is the ability to combine words together and create sentences in order to convey messages, thoughts, and ideas. Speaking English is very important for human interaction where people almost speak everywhere and every day through English. In this global era, many people use English as a medium of communication and it makes people who come from different countries communicate more easily (Efrizal, 2012). Language comprehension depends on success in understanding speech. There are many factors which affect speaking proficiency. All of these factors (e.g. lexical knowledge, accuracy, intonation and accent, fluency, and pronunciation, just to name a few) play a significant role in building one's speaking skills. The focus of this study was on English oral accuracy and fluency as two key factors in speaking. Fluency is regarded as the ability of speaking or writing easily and gracefully. Poor fluency can limit the interaction patterns and may affect the satisfaction of speakers and interlocutors because they practice language in real-time (Kasap, 2005). On the other hand, accuracy refers to the ability of generating and using correct forms or language bases (Skehan, 1998).

Many researchers examined effective methods of teaching second or foreign languages and focused on topics such as roles of grammar, materials, and technology in teaching or developing accuracy and fluency, teaching productive or receptive abilities, and motivating learners (Kalanzade, Mirchenari \& Bakhtiarvand, 2013). Iranian English teachers tend to use different methods in order to facilitate learning the speaking skill in the classroom, but some utilized methodologies which mostly lead to failure (Rahimy \& Safapour, 2012). Many strategies such as watching movies have been applied for improving English language skills, specially speaking. Using subtitles as pedagogical instruments plays an effective role in the process of learning. Subtitling refers to placing text (original or translated) into the pictures and sound by regarding time and space. In addition, many studies have highlighted the effective role of utilizing subtitles on improving language skills as a pedagogical application. Talavan (2010) analyzed the need for pedagogical usage of subtitles and subtitling in the classroom with the goal of improving oral comprehension skills and found it can provide textual, visual and technological support and can improve the oral skill. It could also help students observe creditable input and produce perceptible output. As L2 speaking has a crucial roles in success of English learning, the aim of this study was finding out whether English and Persian subtitles used for teaching English could have any effects on oral accuracy and fluency of intermediate Iranian EFL learners, and if so, which one proved to be more effective than the other. First, the effect of English subtitles on oral fluency and accuracy was measured. Then an attempt made to see if Persian subtitles also could affect speaking fluency and accuracy of the learners. Finding the way to answers and 
solutions for the above-mentioned problems led to defining the research questions for the study, which aimed to compare the effects of English and Persian subtitles on oral accuracy and fluency of intermediate Iranian EFL learners. This study is thus guided by the following research questions:

1. Does the application of English subtitles lead to the improvement of speaking fluency and accuracy of intermediate Iranian EFL learners?

2. Does the application of Persian subtitles lead to the improvement of speaking fluency and accuracy of intermediate Iranian EFL learners?

3. Does the application of subtitling (in its different forms) have any effects on speaking fluency and accuracy of intermediate Iranian EFL learners?

According to Chaney (1998), speaking is the activity of constructing and sharing meaning through the use of verbal and nonverbal signs, in a variety of contexts. The importance of speaking in language learning and teaching is so obvious. For many years, students recited and memorized the dialogs, but today they should learn how to present themselves and follow social and cultural rules in any situation. They can learn to speak in various communicative situations. Public speaking plays an important role from recruitment to persuasion, from informing to initiation. Hence, because of the importance of speech, learning speaking can be effective and lead to more successful results for any group or organization. There are a few basics one must first understand such as different types of speeches and when to use them, the unity of speech, and how to reduce anxiety and increase confidence in public speaking (Ricketts \& Keith, 2013). Accuracy and fluency, which are two key elements in speaking, are presented as a challenge for language learners and teachers. This subject is also confirmed by researchers such as Hunter (2011) who claim that the issue of how to ensure leaners develop accuracy and complexity as well as fluency in their speaking is a challenge for teachers because too much corrective feedback (CF) can make learners reluctant to speak, while not enough may allow their errors to become entrenched.

Nowadays there is a superfluous emphasis on English teaching as a medium of communication, and technology plays a significant role in facilitating communication. Procedures of teaching must be creative and motivating and also provide an entertaining environment for learners who have different level of proficiency. Actually choices of watching movies have become numerous; in other words, employing multimedia has changed educational methods and resources. Using movies can be effective in different areas of language teaching including teaching writing, oral skills, grammar, vocabulary and cultural features. One of these techniques is utilizing subtitles. Subtitles are usually displayed at the bottom of screen and are either a transcript or screenplay of the conversation or narration in films, television programs, or video games. They are either a form of written translation of a dialog in a foreign language or a written text of the dialog in the same language. Some researchers have provided strong evidence that multimedia has useful effects on language learning because of their rich and authentic comprehensible input. Watching captioned films in English are more helpful rather than other authentic input because it is the constitution of aural, pictorial and textual media (Rokni, \& Ataee, 2014a).A great number of studies have been carried out on the ways through which various subtitles have been used to teach English to EFL learners.

In a study, sixty homogeneous students of English literature at university were selected by Ghasemboland and Nafissi (2012) in order to investigate the effect of English captions with an English-language sound track on their listening comprehension. The participants were randomly assigned into experimental group and control group. Both groups were exposed to short episode (20 minutes) of an English film; the experimental group watched the film with English subtitles and the control group watched the film without captions. Then 20-item multiple choice (MC) teacher-made listening-comprehension test were given to them. The results revealed that performance of experimental group was better than that of the control group and that providing captions for Iranian EFL learners could be conducive to improving their listening comprehension.

Rokni and Ataee (2014b) examined the impact of watching English movies with and without subtitles on speaking ability of EFL learners. Thirty-eight intermediate Iranian learners were selected randomly in Gorgan, Iran. Experimental and control groups watched the movies in 20 sessions, each for about 15 minutes and then all the subjects took the speaking posttest. The findings indicated that the improvement of experimental group who watched the films with subtitles in their speaking ability was more considerable than the control group who watched the movie without subtitles.

Y'dewalle (2002) studied the relation of watching subtitled television programs and acquisition of foreign language. He found that younger people read subtitles faster and finish reading earlier, but elderly people complain more than other age groups. Regarding to the shorter subtitles, age-related difference does not occur because nobody has extra time available. Watching subtitled programs involves a person incorporating data from the image, subtitles, and sound; older subjects continuously and after a first reading of subtitles, come back to the image very quickly. The presence of both a speaker and a subtitle made the slowest reaction times with adults and this group of participants must make an effort to understand the speech.

Previous studies demonstrated that the outcome of watching movies with subtitles was more than movies without any captions. In addition, by investigating other research studies, it was found that using subtitles was conducive to vocabulary learning, listening comprehension, speaking ability, and strategies of teaching and translating. Yet, this study attempted to approach the yet untouched question of whether using English and Persian subtitles could lead to the improvement of Iranian EFL learners' speaking accuracy and fluency. 


\section{Methodology}

\subsection{Participants}

To choose the participants for this research, intermediate EFL learners from a language institute in Isfahan were asked to take part in the study. PET was utilized to render a homogeneous sample from among the 100 intermediate EFL at the institute. Those whose PET scores were within one standard deviation above and below the mean were chosen to take part in this study. The selected sample consisted of 60 female native speakers of Persian with an age range of 15 to 20. After explaining the aims of the study to the participants and testing them by PET, the researcher randomly chose one of the groups to be the control group $(\mathrm{CG})$ and the two others as the experimental groups:English subtitling group (ESG)and Persian subtitling group (PSG).

\subsection{Materials and Instruments}

The film which was used in this study was Museums of the World 2 intended for intermediate learners and had both English and Persian subtitles. This film had a geographical-historical subject and comprised 3 DVDs. Three types of instruments, including pretest of fluency and accuracy, posttest, and PET were used in this study. The pretest and posttest took the form of interview in this study in order to understand participants' improvements (if any) in terms of fluency and accuracy, and to gather the required data. Each of these tests comprised oral questions related to the topics such as historical buildings in Isfahan and favorite places for vacations, and the students were expected to answer these questions in a fluent and accurate way. The questions were the almost same for all the students. Measures of fluency and accuracy were used in order to evaluate the ability of oral production of the participants. Then the researchers scored the learners' ability in fluency according to the number of syllables produced per minute of speech. This measure of fluency has been widely used in L2 acquisition studies (e.g., Sabzevari, 2012; Yuan \& Ellis, 2003, to name just a few). For measuring their ability in accuracy, the method suggested and employed by Foster and Skehan (1996) was used. They suggest using error-free clauses as a percentage of the total number of clauses. More specifically, the number of clauses was counted. Then, the number of error-free clauses was counted and accuracy was measured by dividing the number of error-free clauses to the total number of clauses.

\subsection{Procedures}

Prior to the treatment, 100 female students from language school took PET and 60 of them, who obtained scores between one standard deviation above and below the mean, were chosen to participate in this study. Then the participants were randomly divided into three groups, took the pretest, and were exposed to different instructional procedures: a movie with English subtitles was provided for one of the experimental groups (ESG), and the film with Persian subtitles was played for the other experimental group (PSG). However, the film that the control group was exposed to did not have any sort of subtitles (NSG). The treatment was performed during 10 sessions, two sessions per week. The 15-minute-per-session treatment was administered as part of the regular class hours, which took an hour and thirty minutes. Semi-structured interviews about topics such as historical buildings in Isfahan and favorite places for vacation were administered as the pretest (see the questions in Appendix A). After the completion of the treatment sessions, in the posttest stage of the study, the semi-structured interview on the same topics used for the pretest was employed to estimate the accuracy and fluency scores of the participants. Finally, the accuracy and fluency scores of the participants were gauged and the scores were prepared for statistical analysis.

\section{Results}

The present study made use of an experimental design to examine the possible effects of different types of subtitling on intermediate Iranian EFL learners' speaking accuracy and fluency. A total number of 60 homogeneous intermediate learners studying English at Donyaye Sokhan Institute, Isfahan were selected out of 100 intermediate learners at the institute and served as the subjects of the study. The selection took place based on the learners' placement scores on the PET; those who happened to obtain a score between one standard deviation above and below the mean were chosen to take part in this study. The descriptive statistics related to the placement test are shown in Table 3.1 below:

Table 3.1. Descriptive Statistics of the Placement Test Scores

\begin{tabular}{ccccc}
\hline & $\mathrm{N}$ & Mean & Std. Deviation & $\begin{array}{c}\text { Std. } \\
\text { Error Mean }\end{array}$ \\
\hline PET & 100 & 76.43 & 11.84 & .69 \\
\hline
\end{tabular}

The 60 intermediate learners were subsequently divided into three groups of equal size: Control Group (CG), English Subtitling Group (ESG), and Persian Subtitling Group (PSG). All the subjects in different groups took part in an interview pretest, and their fluency and accuracy scores were gauged. The experimental groups received their relevant treatments, while the control group learners watched movies without any type of subtitling. The three groups once again sat for an interview test after the implementation of the experiment. The data obtained were analyzed using the SPSS: paired-samples $t$ test was used to examine the possible improvements from pretest to posttest for research questions 1 and 2. One-way between groups ANOVA was conducted to find an answer to the third research questions of the study. 


\subsection{Results for the First Research Question}

The first research question of the study asked whether English subtitles led to the improvement of speaking fluency and accuracy of intermediate Iranian EFL learners or not. To find an answer to this research question, the fluency and accuracy pretest scores of the participants in the ESG were compared with their fluency and accuracy posttest scores. This enabled the researchers to find out whether the possible differences between the fluency and accuracy pretest and fluency and accuracy posttest scores were statistically significant or not, and thus to understand whether the improvements were considerable or not. Table 3.2 presents the descriptive statistics for the fluency and accuracy pretest and fluency and accuracy posttest scores of the ESG.

Table 3.2 Descriptive Statistics Results Comparing Fluency and Accuracy Pretest and Posttest Scores of the ESG

\begin{tabular}{lllccc}
\hline \multirow{2}{*}{ Fluency } & Groups & $N$ & Mean & Std. Deviation & Std. Error Mean \\
\hline \multirow{2}{*}{ Accuracy } & Pretest & 20 & 1.58 & .16 & .03 \\
\cline { 2 - 6 } & Posttest & 20 & 2.02 & .17 & .03 \\
\hline
\end{tabular}

Comparing the mean scores of the fluency and accuracy pretest and the posttest, it could be seen that for both fluency and accuracy, the posttest mean scores exceeded their pretest counterparts. That is, ESG learners managed to achieve a mean score of 2.02 on the fluency posttest, while their fluency pretest mean score was 1.58. For accuracy, the same thing happened. Their accuracy posttest mean score $(M=4.79)$ was greater than their accuracy pretest mean score $(M=$ 3.11). The significance or insignificance of these differences between the pretest and posttest scores of fluency and accuracy of the ESG could be determined in the $t$ test table below:

Table 3.3 Paired-Samples $t$ Test Results Comparing Fluency and Accuracy Pretest and Posttest Scores of the ESG

\begin{tabular}{|c|c|c|c|c|c|c|c|}
\hline & \multirow[b]{2}{*}{ Mean } & \multirow{2}{*}{$\begin{array}{c}\text { Std. } \\
\text { Deviation. }\end{array}$} & \multirow[b]{2}{*}{$t$} & \multirow[b]{2}{*}{$d f$} & \multirow{2}{*}{$\begin{array}{c}\text { Sig. } \\
\text { (2-tailed) }\end{array}$} & \multicolumn{2}{|c|}{$\begin{array}{l}\text { 95\% Confidence } \\
\text { Interval of the } \\
\text { Difference }\end{array}$} \\
\hline & & & & & & Lower & Upper \\
\hline Fluency Pretest-Posttest & -.43 & .28 & -6.98 & 19 & .000 & -.56 & -.30 \\
\hline Accuracy Pretest-Posttest & 1.67 & .72 & -10.38 & 19 & .000 & -2.01 & -1.34 \\
\hline
\end{tabular}

The Sig. (2-tailed) value represents a $p$ value lower than the significance level $(.000<.05)$ for fluency, indicating that the difference between the pretest and posttest fluency scores of the ESG learners had been statistically significant The same was also true for the pretest and posttest accuracy scores of the learners. This means that English subtitling significantly improved both fluency and accuracy of intermediate Iranian EFL learners and fist null hypothesis cannot be affirmed. This is also graphically shown in the bar chart below.

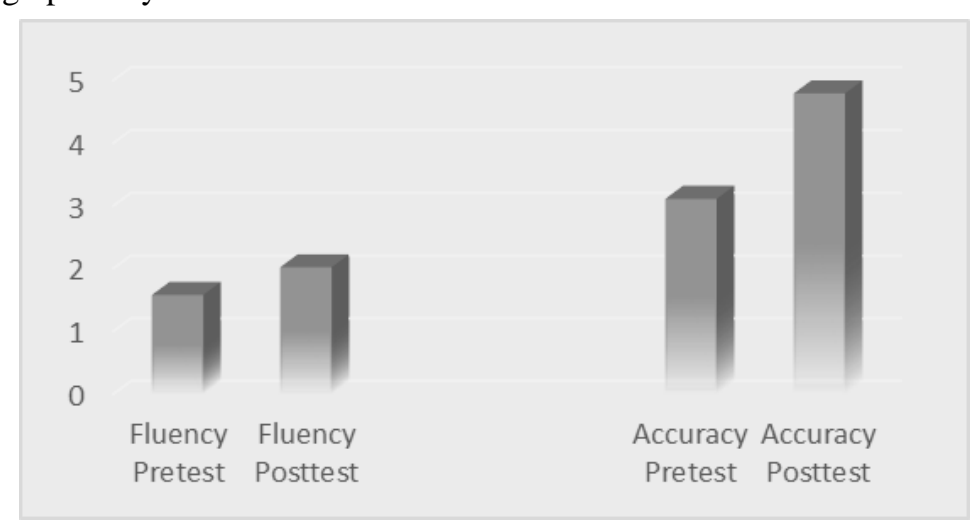

Figure 3.1 The Mean Fluency and Accuracy Scores of ESG on the Pretest and Posttest

It is well beyond doubt that the ESG learners showed better performances on their fluency and accuracy posttests, compared to their fluency and accuracy pretest performances.

\subsection{Results for the Second Research Question}

The second research question of the study investigated whether Persian subtitles led to the improvement of speaking accuracy and fluency of intermediate Iranian EFL learners or not. To find an answer to this research question, the 
fluency and accuracy pretest scores of the participants in the PSG were compared with their fluency and accuracy posttest scores and considered whether the possible differences between the fluency and accuracy pretest and fluency and accuracy posttest scores were statistically significant or not. This enabled the researchers to understand whether the improvements were considerable or not. Table 3.4. displays the descriptive statistics results for the fluency and accuracy pretest and fluency and accuracy posttest scores of the PSG.

Table 3.4 Descriptive Statistics Results Comparing Fluency and Accuracy Pretest and Posttest Scores of the PSG

\begin{tabular}{llcccc}
\hline \multirow{2}{*}{ Fluency } & Groups & $N$ & Mean & Std. Deviation & Std. Error Mean \\
\hline \multirow{2}{*}{ Accuracy } & Pretest & 20 & 1.55 & .15 & .03 \\
\cline { 2 - 6 } & Posttest & 20 & 1.92 & .17 & .03 \\
\hline & Pretest & 20 & 3.12 & .35 & .08 \\
\hline
\end{tabular}

The number of participants, mean scores, standard deviations, etc. are demonstrated in Table 3.4. Comparing the mean scores of the fluency and accuracy pretest and the posttest unfolded that posttest mean scores for fluency and accuracy were greater than their pretest scores. This means that, PSG learners managed to obtain a mean score of 1.92 on the fluency posttest, while their fluency pretest mean score was 1.55 . For accuracy, the same thing was true. Their accuracy posttest mean score $(M=4.72)$ was higher than their accuracy pretest mean score $(M=3.12)$. Whether the difference between pretest and posttest scores of fluency and accuracy of the PSG is significant or not is reflected in the $t$ test table below.

Table 3.5 Paired-Samples $t$ Test Results Comparing Fluency and Accuracy Pretest and Posttest Scores of the PSG

\begin{tabular}{|c|c|c|c|c|c|c|c|}
\hline & \multirow[b]{2}{*}{ Mean } & \multirow{2}{*}{$\begin{array}{c}\text { Std. } \\
\text { Deviation }\end{array}$} & \multirow[b]{2}{*}{$t$} & \multirow[b]{2}{*}{$d f$} & \multirow{2}{*}{$\begin{array}{c}\text { Sig. } \\
\text { (2-tailed) }\end{array}$} & \multicolumn{2}{|c|}{$\begin{array}{l}\text { 95\% Confidence } \\
\text { Interval of the } \\
\text { Difference }\end{array}$} \\
\hline & & & & & & Lower & Upper \\
\hline Fluency Pretest-Posttest & -.36 & .25 & -6.48 & 19 & .000 & -.48 & -.24 \\
\hline Accuracy Pretest-Posttest & 1.59 & .81 & -8.79 & 19 & .000 & -1.97 & -1.21 \\
\hline
\end{tabular}

The Sig. (2-tailed) value represents a $p$ value lower than the significance level $(.000<.05)$ for fluency, demonstrating that the difference between the pretest and posttest fluency scores of the PSG learners had been statistically significant. In addition, the difference between the pretest and posttest accuracy scores of the learners had been statistically significant. This means that Persian subtitling significantly improved both fluency and accuracy of intermediate Iranian EFL learners. Figure 3.2 illustrates the aforementioned differences.

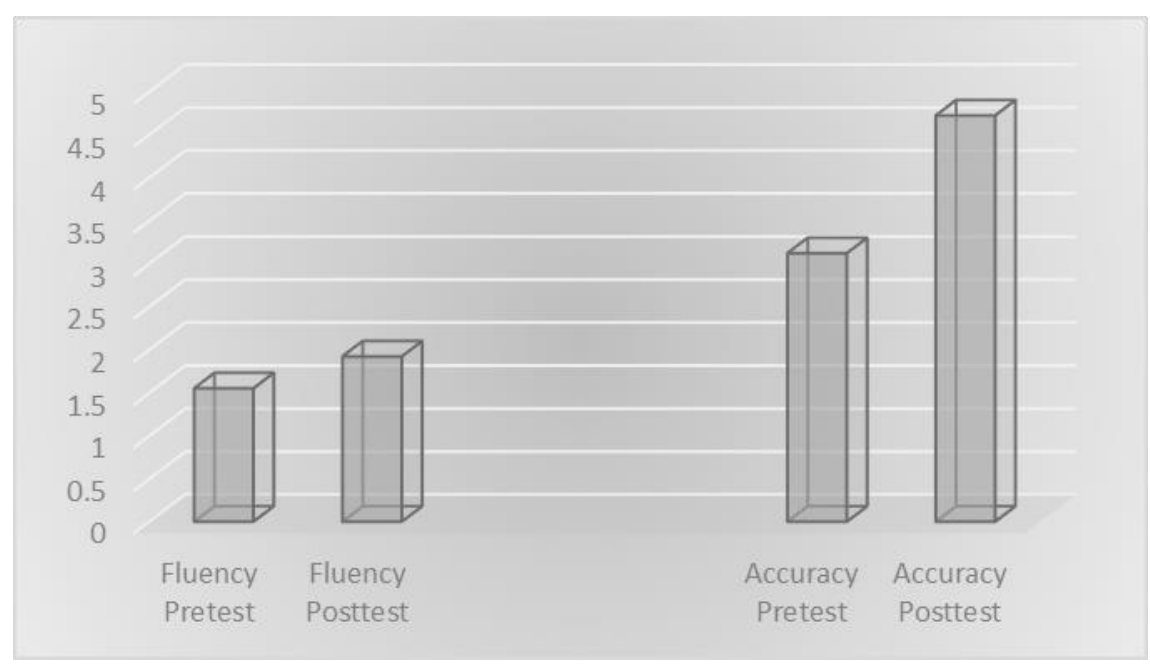

Figure 3.2 The Mean Fluency and Accuracy Scores of PSG on the Pretest and Posttest

It is obvious that the performances of the PSG learners on their fluency and accuracy posttests were better than their fluency and accuracy pretest performances. 


\subsection{Results for the Third Research Question}

One of the aims of the study was to find out whether subtitling (in its different forms) had any effect on speaking accuracy and fluency of intermediate Iranian EFL learners. To achieve this aim, one-way between groups ANOVA was conducted four times: once for the comparison of the fluency pretest scores of the three groups at the beginning of the study, and once again for the comparison of the accuracy pretest scores of those groups at the outset of the study. Moreover, one-way ANOVA was used for comparing these groups' fluency and accuracy posttest scores. What follow is the results of the related analyses.

\subsubsection{Pretest Result}

The results of the comparison of the three groups on the fluency pretest are displayed in Tables 3.6, and 3.7.

Table 3.6 Descriptive Statistics Results Comparing CG, ESG, and PSG Mean Scores on the Fluency Pretest

\begin{tabular}{lcccccccc}
\hline \multicolumn{10}{c}{ 95\% Confidence Interval for } \\
& & \multicolumn{8}{c}{ Mean } \\
\hline & $N$ & Mean & Std. Deviation & Std. Error & $\begin{array}{c}\text { Lower } \\
\text { Bound }\end{array}$ & $\begin{array}{c}\text { Upper } \\
\text { Bound }\end{array}$ & Minimum & Maximum \\
\hline CG & 20 & 1.56 & .17 & .038 & 1.47 & 1.64 & 1.20 & 1.86 \\
\hline ESG & 20 & 1.58 & .16 & .036 & 1.50 & 1.66 & 1.21 & 1.86 \\
\hline PSG & 20 & 1.55 & .15 & .035 & 1.48 & 1.63 & 1.20 & 1.80 \\
\hline Total & 60 & 1.56 & .16 & .020 & 1.52 & 1.60 & 1.20 & 1.86 \\
\hline
\end{tabular}

The fluency pretest mean scores of the CG $(M=1.56)$, ESG $(M=1.58)$, and PSG $(M=1.55)$ were different from one another. To figure out whether the differences among these mean scores were significant or not, one needs to check the $p$ value under the Sig. column in the ANOVA table below.

Table 3.7 Results of One-Way ANOVA for Comparing CG, ESG, and PSG Mean Scores on the Fluency Pretest

\begin{tabular}{llllll}
\hline & Sum of Squares & $d f$ & Mean Square & $F$ & Sig. \\
\hline Between Groups & .009 & 2 & .005 & .16 & .84 \\
\hline Within Groups & 1.54 & 57 & .027 & & \\
\hline Total & 1.55 & 59 & & & \\
\hline
\end{tabular}

As is displayed in Table 3.7, there was not a statistically significant difference in the fluency pretest scores for CG $(M=$ $1.56, S D=.17)$, ESG $(M=1.58, S D=.16)$, and PSG $(M=1.55, S D=.15)$ because the $p$ value under the Sig. column was greater than the specified level of significance (i.e. $.84>.05$ ), indicating that the three groups did not significantly differ prior to the commencement of the experiment. This made the three groups comparable in terms of fluency. This result is also evident in the bar chart below.

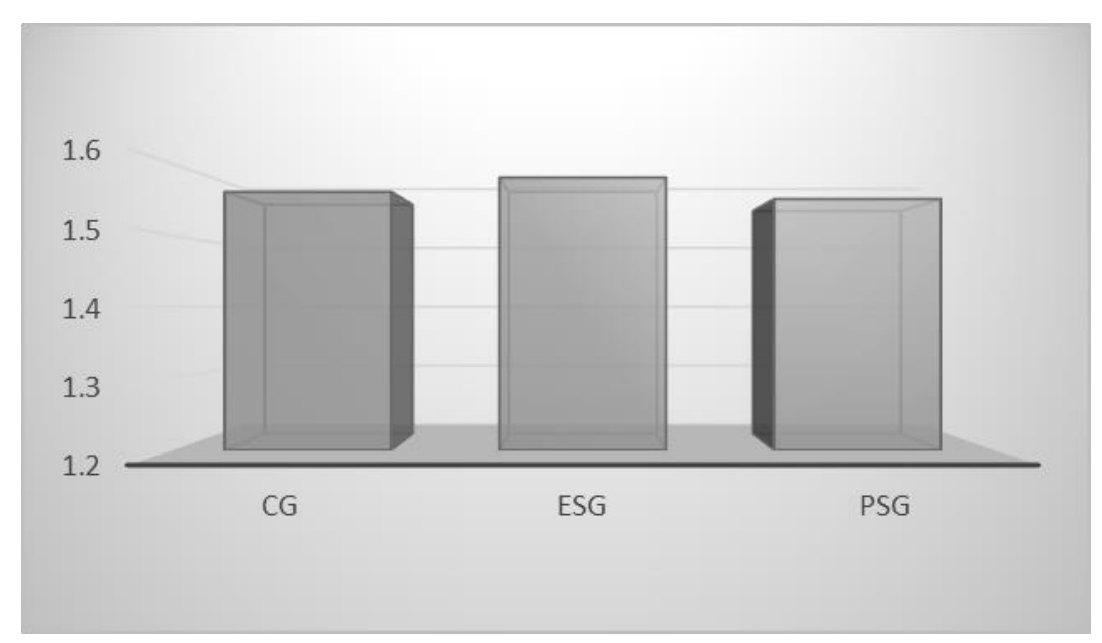

Figure 3.3 The Mean Scores of CG, ESG, and PSG on the Fluency Pretest 
This bar chart elucidates the fact that the differences among the three groups on the fluency pretest were not considerable. Tables 3.8 and 3.9 compare the accuracy pretest scores of the three groups.

Table 3.8 Descriptive Statistics Results Comparing CG, ESG, and PSG Mean Scores on the Accuracy Pretest

\begin{tabular}{lcccccccc}
\hline & \multicolumn{8}{c}{$\begin{array}{c}\text { 95\% Confidence Interval } \\
\text { for Mean }\end{array}$} \\
& $N$ & Mean & Std. Deviation & Std. Error & Lower Bound & $\begin{array}{c}\text { Upper } \\
\text { Bound }\end{array}$ & Minimum & Maximum \\
\hline CG & 20 & 3.111 & .339 & .075 & 2.95 & 3.27 & 2.32 & 3.66 \\
\hline ESG & 20 & 3.112 & .353 & .079 & 2.94 & 3.27 & 2.32 & 3.69 \\
\hline PSG & 20 & 3.125 & .358 & .080 & 2.95 & 3.29 & 2.28 & 3.70 \\
\hline Total & 60 & 3.116 & .344 & .044 & 3.02 & 3.20 & 2.28 & 3.70 \\
\hline
\end{tabular}

The accuracy pretest mean scores of the CG $(M=3.111)$, ESG $(M=3.112)$, and PSG $(M=3.125)$ were different from one another. To figure out whether the differences among these mean scores were significant or not, one needs to check the $p$ value under the Sig. column in the ANOVA table below.

Table 3.9 Results of One-Way ANOVA for Comparing CG, ESG, and PSG Mean Scores on the Accuracy Pretest

\begin{tabular}{lccccc}
\hline & Sum of Squares & $d f$ & Mean Square & $F$ & Sig. \\
\hline Between Groups & .002 & 2 & .001 & .010 & .99 \\
\hline Within Groups & 7.007 & 57 & .123 & & \\
\hline Total & 7.010 & 59 & & & \\
\hline
\end{tabular}

As is displayed in Table 3.9, there was not a statistically significant difference in the accuracy pretest scores for CG ( $M$ $=3.111, S D=.339)$, ESG $(M=3.112, S D=.353)$, and PSG $(M=3.125, S D=.358)$ because the $p$ value under the Sig. column was greater than the specified level of significance (i.e. $.99>.05$ ), indicating that the three groups did not significantly differ prior to the commencement of the experiment with regards to accuracy. This made the three groups comparable in terms of speaking accuracy. This result is also evident in the bar chart below.

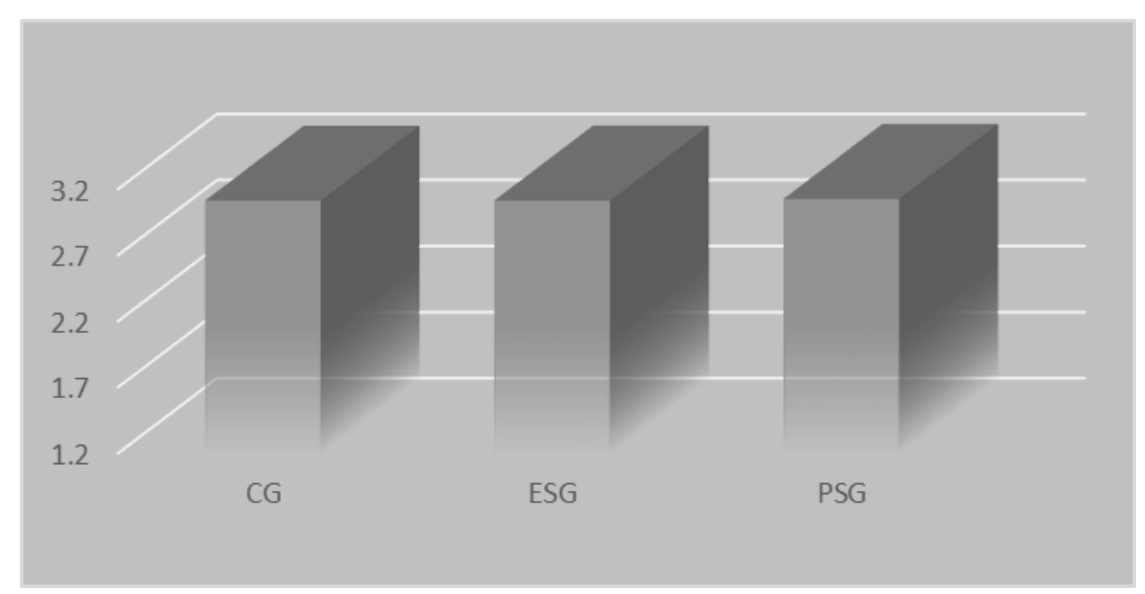

Figure 3.4 The Mean Scores of CG, ESG, and PSG on the Accuracy Pretest

This bar chart elucidates the fact that the differences among the three groups on the accuracy pretest were not considerable.

\subsubsection{Posttest Results}

The results obtained upon the administration of the posttest are presented in this section. Table 3.10 shows the descriptive statistics for the comparison of the three groups on the fluency posttest. 
Table 3.10 Descriptive Statistics Results Comparing CG, ESG, and PSG Mean Scores on the Fluency Posttest

\section{$95 \%$ Confidence Interval}

for Mean

\begin{tabular}{lcccccccc}
\hline & $N$ & Mean & $\begin{array}{c}\text { Std. } \\
\text { Deviation }\end{array}$ & Std. Error & $\begin{array}{c}\text { Lower } \\
\text { Bound }\end{array}$ & $\begin{array}{c}\text { Upper } \\
\text { Bound }\end{array}$ & Minimum & Maximum \\
\hline CG & 20 & 1.58 & .14 & .03 & 1.51 & 1.65 & 1.32 & 1.89 \\
\hline ESG & 20 & 2.02 & .17 & .03 & 1.93 & 2.10 & 1.73 & 2.28 \\
\hline PSG & 20 & 1.92 & .17 & .03 & 1.83 & 2.00 & 1.64 & 2.15 \\
\hline Total & 60 & 1.84 & .25 & .03 & 1.77 & 1.90 & 1.32 & 2.28 \\
\hline
\end{tabular}

Based on Table 3.10, the mean scores of the CG $(M=1.58)$, ESG $(M=2.02)$, and PSG $(M=1.92)$ were different from each other. To find out whether the differences among these mean scores were of statistical significance or not, one should look down the Sig. column Table 3.11 below.

Table 3.11 Results of One-Way ANOVA for Comparing CG, ESG, and PSG Mean Scores on the Fluency Posttest

\begin{tabular}{lccccc}
\hline & Sum of Squares & $d f$ & Mean Square & $F$ & Sig. \\
\hline Between Groups & 2.134 & 2 & 1.067 & 37.86 & .000 \\
\hline Within Groups & 1.606 & 57 & .028 & & \\
\hline Total & 3.740 & 59 & & \\
\hline
\end{tabular}

As could be seen in Table 3.11, there was a statistically significant difference in posttest fluency scores for CG $(M=$ $1.58, S D=.14)$, ESG $(M=2.02, S D=.17)$, and PSG $(M=1.92, S D=.17)$ since the $p$ value under the Sig. column was less than the specified level of significance (i.e. $.000<.05)$. To find out where exactly the differences among the three groups lay, the Scheffe post hoc test was conducted.

Table 3.12 Results of the Scheffe Post Hoc Test for Comparing CG, ESG, \& PSG Mean Scores on the Fluency Posttest

\begin{tabular}{llccccc}
\hline Groups & & Mean Difference & Std. Error & Sig. & \multicolumn{2}{c}{ 95\% Confidence Interval } \\
\hline & & & & & Lower Bound & Upper Bound \\
\hline CG & ESG & $-.44^{*}$ & .05 & .000 & -.57 & -.30 \\
& PSG & $-.33^{*}$ & .05 & .000 & -.47 & -.20 \\
& & & & & & .57 \\
\hline ESG & CG & $.44^{*}$ & .05 & .000 & .30 & .23 \\
& PSG & .10 & .05 & .170 & -.03 & .47 \\
& CG & $.33^{*}$ & .05 & .000 & .20 & .03 \\
\hline
\end{tabular}

In the top row, it could be seen that the CG was significantly different from the ESG and PSG. This means that the two experimental groups outperformed the CG on the fluency posttest. However, there was not a significant difference between ESG and PSG in terms of their fluency. The obtained results of this part are also shown in the bar chart below.

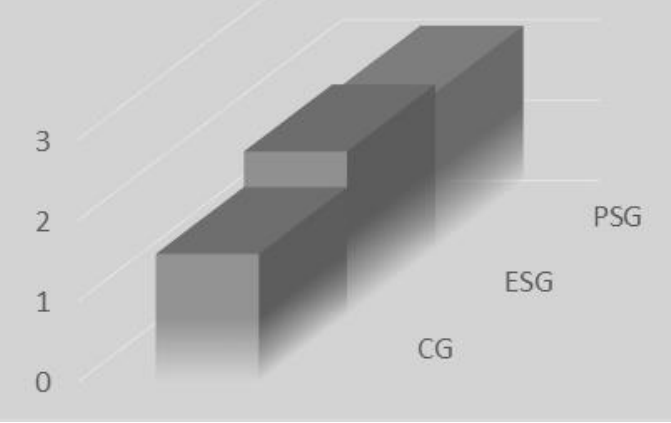

Figure 3.5 The Mean Scores of CG, ESG, and PSG on the Fluency Posttest 
It is clear that the experimental groups could gain significantly better mean scores on the fluency posttest than the CG, and that English subtitling was (although not significantly) better than Persian subtitling. Table 3.13 shows the mean scores of the three groups on the accuracy posttest.

Table 3.13 Descriptive Statistics Results Comparing CG, ESG, and PSG Mean Scores on the Accuracy Posttest

\begin{tabular}{lcccccccc}
\hline & \multicolumn{7}{c}{$\begin{array}{c}90 \\
\text { Interval for Mean }\end{array}$} \\
\hline & $N$ & Mean & Std. Deviation & Std. Error & $\begin{array}{l}\text { Lower } \\
\text { Bound }\end{array}$ & $\begin{array}{c}\text { Upper } \\
\text { Bound }\end{array}$ & Minimum & Maximum \\
\hline CG & 20 & 3.26 & .33 & .07 & 3.10 & 3.41 & 2.44 & 3.76 \\
\hline ESG & 20 & 4.79 & .60 & .13 & 4.50 & 5.07 & 3.23 & 5.50 \\
\hline PSG & 20 & 4.72 & .69 & .15 & 4.39 & 5.04 & 3.12 & 5.64 \\
\hline Total & 60 & 4.25 & .90 & .11 & 4.02 & 4.49 & 2.44 & 5.64 \\
\hline
\end{tabular}

Table 3.13 demonstrated the differences among the mean scores of the CG $(M=1.58)$, ESG $(M=2.02)$, and PSG $(M=$ 1.92) from each other. To figure out whether the differences among these mean scores were statistically meaningful or not, one should glance up the Sig. column Table 3.14 below.

Table 3.14 Results of One-Way ANOVA for Comparing CG, ESG, and PSG Mean Scores on the Accuracy Posttest

\begin{tabular}{lccccc}
\hline & Sum of Squares & $d f$ & Mean Square & $F$ & Sig. \\
\hline Between Groups & 29.89 & 2 & 14.94 & 46.85 & .000 \\
\hline Within Groups & 18.185 & 57 & .319 & & \\
\hline Total & 48.082 & 59 & & \\
\hline
\end{tabular}

Based on the Table 3.14, the $p$ value under the Sig. column was less than the specified level of significance (i.e. .000 $<.05)$ and statistically significant differences in posttest fluency scores for CG $(M=1.58, S D=.14)$, ESG $(M=2.02, S D$ $=.17)$, and PSG $(M=1.92, S D=.17)$ were indicated. To find out the exact locations of the differences among the three groups, the Scheffe post hoc test was conducted.

Table 3.15 Results of the Scheffe Post Hoc Test for Comparing CG, ESG, \& PSG Mean Scores on the Accuracy Posttest

\begin{tabular}{llccccc}
\hline Groups & & Mean Difference & Std. Error & Sig. & \multicolumn{2}{c}{$95 \%$ Confidence Interval } \\
\hline & & & & & Lower Bound & Upper Bound \\
\hline CG & ESG & $-1.53^{*}$ & .17 & .000 & -1.97 & -1.08 \\
& PSG & $-1.46^{*}$ & .17 & .000 & -1.91 & -1.01 \\
\hline ESG & CG & $.1 .53^{*}$ & .17 & .000 & 1.08 & 1.97 \\
& PSG & .06 & .17 & .929 & -.38 & .51 \\
\hline PSG & CG & $1.46^{*}$ & .17 & .000 & 1.01 & 1.91 \\
& ESG & -.06 & .17 & .929 & -.51 & .38 \\
\hline
\end{tabular}

In the top row, it could be seen that there is a significant difference between the CG on the one hand and the ESG and PSG on the others. This means that the performances of the two experimental groups were better than the CG on the fluency posttest. However, difference between ESG and PSG in terms of their fluency was not significant. The obtained results of this part are also shown in the bar chart below. 


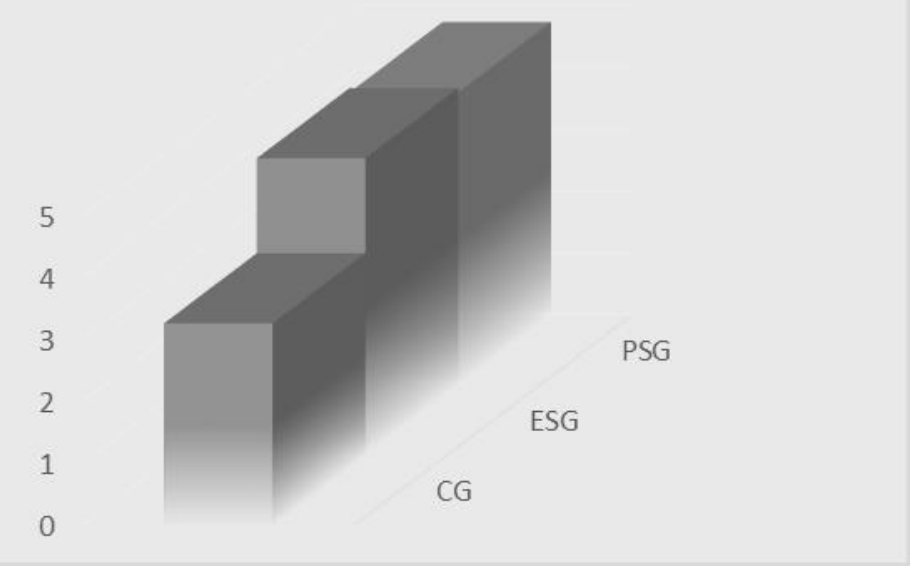

Figure 3.6 The Mean Scores of CG, ESG, and PSG on the Accuracy Posttest

It is evident that the performance of experimental groups significantly better than the CG on the fluency posttest, and scores of English subtitling was (although not significantly) better than Persian subtitling. The third null hypothesis in the study is rejected.

\section{Discussion and Conclusion}

\subsection{Discussion}

The lack of research about the impacts of using English and Persian subtitles on oral fluency and accuracy of intermediate Iranian EFL learners was felt in the literature and thus this incentive lead to carrying out the present study. What can be construed from the findings of this study is that using different kinds of subtitles seemed to have positive effects on developing oral fluency and accuracy. Although there were no significant differences between groups at the beginning of the research, the scores of experimental groups were higher than those of the control group in the posttest. These results support the effectiveness of using subtitles. These obtained results are discussed and compared with the relevant previous studies below.

\subsubsection{Discussing the First Research Question}

Probably the reason why ESG learners improved their accuracy was that they were exposed to grammatical structures of English not only through the auditory channel but also through the visual channel. In other words, they could both see and hear the correct grammatical structures of English. In addition, their fluency ameliorated probably because they could see English sentences on the screen chunk by chunk. This might have led to the learners' improved fluency. Most subtitling studies have been about the effects of using subtitles focused on speaking ability in general, strategies, listening comprehension, acquisition of foreign language, etc. and less attention has been paid to investigating oral fluency and accuracy. Etemadi (2012) reports that most of previous research mentioned and confirmed the effective and facilitative role of using subtitles on vocabulary learning, listening comprehension and language learning in general, and thus using subtitles for oral accuracy and fluency deserved exploration.

Beauprez (2014), Ina (2014), and Raine (2012) showed the positive effects of subtitling on L2 vocabulary acquisition of EFL/ESL learners. In addition, Janfaza, Javidi and Soori (2014) found subtitling fruitful for L2 listening comprehension. The results of the present study lend support to those previous studies in that they also demonstrated the promising effects of subtitling. In fact, English subtitling was shown to exert positive influences on both fluency and accuracy of intermediate Iranian EFL learners. Regarding L2 fluency, Yurong and Nan (2008) asserted that motivation, anxiety, and self-esteem were contributing factors as well. Also, Ascione (1993) claimed that supportive parents and teachers' attitudes, L2 proficient teachers, L2 immersion learning environment, and sociable classmates could bring about positive changes in L2 learners of fluency. The results obtained here suggested that in addition to the above mentioned factors, English subtitling could also promote fluency of EFL learners.

\subsubsection{Discussing the Second Research Question}

Data analysis conducted for the second research question revealed that PSG learners' posttest scores were better than their pretest scores and the differences were significant. Consequently, Persian subtitles could improve speaking fluency and accuracy and thus the second null hypothesis was declined as well. Persian subtitles provided an opportunity for students to comprehend better and know the exact meaning of vocabularies and phrases. They were familiarized and compared Persian equivalences with English voices and could apply them accurately and fluently in conversation.Previous studies unfolded the positive effects of subtitling on vocabulary learning (Rostam-Shirazi, Hesabi, \& Simin, 2015), listening comprehension (Ghasemboland \& Naffisi, 2012; Latif, Mohammadi, \& Youhanaee, 2012), and speaking (Rokni \& Ataeei, 2014). Likewise, the results of the current study revealed positive impacts of subtitling on speaking fluency and accuracy. 


\subsubsection{Discussing the Third Research Question}

To achieve the answer to this question, fluency pretest scores of ESG, PSG and CG were compared and it was concluded that there were no significant differences among CG, PSG and ESG at the beginning of the study; then the accuracy pretest scores of these groups were considered for comparison and it was found that the differences among groups were not statistically significant. Finally, fluency and accuracy posttest scores of these three groups were analyzed. It was found that oral fluency and accuracy did not considerably change in the control group, but there were significant improvements in English subtitle and Persian subtitle groups on oral fluency and accuracy. The improvements of ESG on fluency and accuracy were much little better, and it seems because both the main language of movie and subtitles were English and acquainted students with more vocabulary, supported them in the understanding of speech, and encouraged them to speak. The third hypothesis was refuted as well.

As it was referred to in 4.1.1 and 4.1.2, subtitling was found to leave positive impacts on different skills and sub-skills of language like vocabulary (Beauprez 2014; Ina 2014; Raine 2012; Rostam shirazi, et al., 2015), listening comprehension (Ghasemboland \& Naffisi, 2012; Janfaza, et al., 2014; Latifi, et al., 2012), and speaking (Rokni \& Ataeei, 2014). Subtitling in its various forms turned out to be conducive to speaking fluency and accuracy.

\section{Conclusion}

We live in an era that technology plays an important role in peoples' lives and interactions. So, it seems that using technology as a tool in pedagogical fields and education can help learners and teachers. Learning each skill of languages has unique challenges. Using films and subtitles is one of these applicable methods for facilitating the process of learning. Previous research studies considered the effects of using subtitles on vocabulary learning, speaking ability, listening comprehension, linguistic and ethnical interactions, and acquisition of foreign language. This study focused on learners' speaking skill and the aim was investigation of the effect ofsubtitling of different forms on the development of oral accuracy and fluency of intermediate Iranian EFL learners. The findings of this research study displayed the substantial positive effects of English and Persian subtitles on improvement of Iranian EFL learners' oral fluency and accuracy, but failed to show significant differences between the experimental groups. These could have implications for second language teachers (and learners as well): They are recommended to make use of English subtitles, where possible, to boost they fluency and accuracy skills; in contrary, where English subtitles have more debilitative than facilitative effects, Persian subtitles could be employed and roughly similar could be obtained.

\section{References}

Ascione, M. (1993). Fluency development in second language teaching. Masters' Thesis. University of Lethbridge, Lethbridge, Canada.

Beauprez, Ch. (2014). The influence of subtitles on the vocabulary acquisition of Flemish students prior to the instruction of English. Masters' Thesis. Gent, Belgium.

Chaney, A.L. (1998). Teaching oral communication. Boston: Allyn and Bacon.

Efrizal, D. (2012). Improving students' speaking through communicative language teaching method.International Journal of Humanities and Social Science, 2(20), 127-134.

Etemadi, A. (2012). Effects of bimodal subtitling of English movies on content comprehension and recognition. International Journal of English Linguistics, 2(1),239-248.

Foster, P. \& Skehan, P. (1996). The influence of planning and task type on second language performance. Studies in Second Language Acquisition, 18, 299-323.

Ghasembolandi, F. \& Nafissi, Z. (2012). The effects of using English captions on Iranian EFL students' listening comprehension. Procedia - Social and Behavioral Sciences, 64, 105- 112.

Hunter, J. (2011). Small talk: Developing fluency, accuracy and complexity in speaking. ELT Journal, 66(1), 1-12.

Ina, L. (2014). Incidental foreign language acquisition by children watching subtitled television programs. The Turkish Online Journal of Educational Technology, 13(4), 81-87.

Janfaza, A., Javidi, S., \& Soori, A. (2014). The impacts of captioned movies on listening comprehension. International Journal of Education \& Literacy Studies, 2(2), 80-84.

Kalanzadeh, G.A., Mirchenari, N.A., \& Bakhtiarvand, M. (2013). Perceived problems in using communicative language teaching (CLT) by EFL Iranian teachers. The International Journal of Language Learning and Applied Linguistics World, 2(3), 5-16.

Kasap, B. (2005). The effectiveness of task-based instruction in the improvement of learners' speaking skills. Masters' thesis. Bilkent, Ankara.

Latifi, M., Yuhanaee, M., \& Mohammadi, E. (2012). The effect of using movie scripts as an alternative to subtitles: How to improve listening comprehension. Porta Linguarum, 22, 203-217.

Rahimy, R. \& Safapour, S. (2012). The effect of using role-play on Iranian EFL learners' speaking ability. Asian Journal of Social Sciences \& Humanities, 1(3), 150-159. 
Raine, P. (2012). Incidental learning of vocabulary through subtitled authentic videos. Masters' thesis. Birmingham, United Kingdom.

Ricketts, K.G. \& Keith, K. (2013). Speaking for success. University of Kentucky, College of Agriculture, Retrieved May 12, 2015 from www.ca.uky.edu.

Rokni, A. \& Ataee, A. (2014a). Movies in EFL classroom: With or without Subtitles. The Dawn Journal, 3(1), 715-726.

Rokni, J. \& Ataee, A. (2014b). The effect of movie subtitles on EFL learners' oral performance. International Journal of English Language, Literature and Humanities, 1(5), 201-215.

Rostam Shirazi, R., Hesabi, A., \& Simin, Sh. (2015). Effects of pedagogical movie English subtitles on EL learners' vocabulary improvement. International Journal of Research Studies in Language Learning,4(5), 10.

Sabzevari, A. (2012). Simultaneous effects of pre-task and on-line planning on complexity, accuracy, and fluency in L2 oral production of Iranian EFL learners. Science Series Data Report, 4(5), 86-101.

Skehan, P. (1998). A cognitive approach to language learning. Oxford: Oxford University Press.

Talaván, N. (2010). Subtitling as a task and subtitles as support: Pedagogical applications. In J. Díaz-Cintas, A. Matamala \&J. Neves (Eds.), New Insights into Audiovisual Translation and Media Accessibility (pp. 285-299). Amsterdam: Rodopi.

d'Ydewalle, G. (2002). Foreign-language acquisition by watching subtitled television programs. Journal of Foreign Language Education and Research 12, 59-77.

Yuan, F. \& Ellis, R. (2003). The effects of pre-task planning and on-line planning on fluency, complexity and accuracy in second language monological oral production. Applied Linguistics, 24(1), 1-27.

Yurong, Zh. \& Nan, Y. (2008). The effects of affective factors on oral English fluency of college English students. Celea Journal, 31(2), 107-116.

\section{Appendix A: Some of Pretest and Posttest Questions}

1. If you decide to travel to Isfahan, how much time do you prefer to spend there and why?

2. Which one is most interesting for you in Isfahan, historical buildings or nature and why?

3. What would be the most exciting and interesting activity in your trip and why?

4. If you want to have a better trip to Isfahan, what kind of information and sources can help you and what should you do to obtain them?

5. What do you know about the history, business, customs and traditions, and cultures in Isfahan? 